\title{
64, UM GOLPE DE CLASSE? (Sobre um livro de René Dreifuss) ${ }^{*}$
}

MARIA VICTORIA BENEVIDES

O fenômeno não é novo e se expande, diariamente, no espaço de polêmicas muitas vezes marcadas pela ausência do mais elementar senso do ridículo. Se, como registra a imprensa, a recente "guerra das tetas"1 foi absorvida, perdura no ar a "santa ira" empresarial contra os impulsos estatizantes dos governos militares. A leitura do livro de René Dreifuss vem a calhar no âmago desta nova perplexidade. Afinal, de que se queixam os empresários? Pois se estão na ordem do dia como estrelas de primeira grandeza... isto é, brilham, na análise de Dreifuss, como os principais artifices das conspirações de 64: "um movimento de classe, e não um mero golpe militar". Será que se queixam porque consideram traídos os objetivos da revolução ou por não terem compreendido, a tempo, que a "regeneração capitalista" que pleiteavam só se faria em virtude da própria ideologia do desenvolvimento com segurança nacional - dentro de um projeto estatizante a longo prazo, também apoiado no grande capital?

Este livro propõe uma nova abordagem de 64 como a estratégia bem sucedida da "desestabilização" do regime populista de João Goulart pela ação de uma elite orgânica - formada por empresários e tecnoem-

\footnotetext{
* Comentário do livro de René Armand Dreifuss, 1964: A conquista do Estado (Ação política, poder e golpe de classe). Petrópolis, Vozes, 1981. (Tradução da tese "State, Class and the Organic Elite: the Formation of an Entrepeneurial Order in Brazil-1961-1965"). O presente texto foi publicado originalmente em Leia Livros, por ocasião do lançamento da obra. Para além da importância intrínseca desta análise há muito inacessível, ela vem publicada aqui como expressão do respeito pela contribuição ao conhecimento de fase crítica da história brasileira recente que devemos ao recentemente falecido René Dreifuss. (N. R.).

1 (1) Referência ao imbroglio causado pela declaração do Ministro Delfim Netto de que os empresários reclamavam, mas viviam "dependurados nas tetas do governo". Junho de 1981.
} 
presários, intelectuais e militares, representantes de interesses financeiros multinacionais e associados - exercendo seu poder de classe. $O$ papel relevante comumente atribuído às Forças Armadas, assim como à "tecnoburocracia", passa a ser atribuído aos empresários, e banqueiros. O complexo IPES/IBAD teria sido o núcleo ativo desse "golpe de classe", cujos objetivos seriam, entre outros, restringir a organização das classes trabalhadoras; consolidar o crescimento econômico num modelo de capitalismo tardio, dependente, com alto grau de concentração industrial integrado ao sistema bancário e promover o desenvolvimento de interesses multinacionais e associados na formação de um regime tecnoempresarial, "protegido e apoiado pelas Forças Armadas". Originalmente apresentado como tese de doutoramento em Ciência Política na Universidade de Glasgow, o trabalho de René Dreifuss reúne as qualidades de competente e ampla pesquisa ao interesse de uma análise política instigante.

O complexo IPES/IBAD é apresentado, na tese de Dreifuss, como o verdadeiro partido da burguesia - no sentido gramsciano - seu EstadoMaior para a ação ideológica, política e militar. O que isso parece significar senão a descrença - quando não o desprezo - que a elite orgânica nutria pelos partidos políticos, comprometidos, em maior ou menor grau, com um Estado populista e tradicional? No entanto, esse desprezo era também relativo, na medida em que se reconhecia a importância do Legislativo como esfera legitimadora - o que fica patente na ação agressiva ao do IBAD nos diversos lobbies nas campanhas eleitorais de 1962 em todo o país. Um dos grandes méritos da pesquisa de Dreifuss consiste, justamente, em revelar a estreita ligação entre o IPES e o IBAD. Lembre-se que, à época em que foi fundado (novembro de 1961, após a renúncia de Jânio e ascensão de Goulart à presidência), o IPES vinha marcado por inegável respeitabilidade. Suas propostas espelhavam o prestígio dos projetos da "Aliança para o Progresso", a qual só seria desmascarada por Che Guevara em 1962, na Conferência de Punta del Este. Ao IBAD, estigmatizado desde o início, competia o "jogo sujo", da manipulação de recursos de fontes equívocas para financiar campanhas dos candidatos conservadores e "corrupções" de vários calibres. As evidências apresentadas por Dreifuss conseguem aproximar as duas entidades, o que a CPI do IBAD tentou em 1963, mas não logrou fazer. ${ }^{2}$

Num de seus artigos do final dos anos setenta, Otto Lara Resende se referia à safra de estudos críticos sobre nossa recente história política dizendo:

2 Agradeço às sugestões de José Gregori. 
"O Brasil se confessa". E o udenista Afonso Arinos, ilustre representante dos liberais desencantados com os rumos militares e estatizantes pós-64, seria particularmente explícito: "precisamos ir ao confessionário". Esta postura de "acerto de contas", ou de mauvaise conscience, talvez contribua para, fazendo eco à repercussão em certos órgãos da imprensa, deformar o real significado do êxito do livro de René Dreifuss. O “quem é quem”, tão ao gosto da curiosidade superficial do nosso crônico provincianismo, deveria ser, é claro, menos relevante do que a discussão das teses do cientista político. Muito mais importante do que "checar" nomes nas listas dos associados do IPES (e vários dos citados tiveram participação meramente acidental), é perceber, no texto, a sólida articulação entre empresários, intelectuais, técnicos e militares em autênticos grupos de pressão, e não em simples conspirações. Quando se entrega um livro ao público nunca se sabe o uso que lhe será dado. É bem possível que aos militares liderados pelo General Golbery tenha agradado o reconhecimento de seu alto grau de eficácia como agentes ativos numa revolução, e não numa quartelada. Aos empresários (incluindo aqueles que têm feito publicar curiosos desmentidos) deve também ter agradado o papel de intelectuais orgânicos desta "revolução burguesa". Enganam-se, senhores. A tese é clara, e a continuidade do processo na já chamada "década da infâmia" (pós AI-5), provaria que, sob qualquer ângulo que se observe, a elite orgânica se sai mal... Quanto aos empresários, ou já sabiam dos rumos da revolução (a estatização e a repressão) e se tornaram, portanto, cúmplices do arbítrio e do "estatismo selvagem" (na expressão recente de um indignado representante da classe), ou não sabiam e se mostravam incompetentes, sem uma clara visão do processo histórico. Quanto aos militares, muito ainda precisa ser esclarecido, além da hipótese que reduz seu importante papel no movimento de 64.

A idéia autoritária da necessidade de um Estado forte sempre esteve presente nas formulações dos militares, atentos às questões de soberania, do desenvolvimento com segurança nacional. É aqui que a densa exposição de Dreifuss me parece pouco clara. A valorização do papel dos empresários é demonstrada de várias maneiras, sempre convincentes e muito bem documentadas - embora de uma perspectiva mais expositiva do que interpretativa. A crítica aos autores que privilegiam o papel dos militares em 64 me parece menos convincente. Pois a própria discussão do autor sobre o papel da Escola Superior de Guerra tenderia a revelar o contrário. Senão, vejamos:

Instrumento para o estabelecimento de ligações orgânicas entre militares e civis, tanto no aparelho estatal quanto nas empresas privadas (...) os industriais e tecno-empresários ligados à estrutu- 
ra multinacional transmitiam e recebiam treinamento em administração pública e objetivos empresariais na ESG(...) compartilhando a ideologia da segurança nacional de seus equivalentes, esses empresários viam a disciplina e a hierarquia como componentes essenciais de um sistema industrial (p. 80).

Esta questão remete à discussão sobre a natureza do Estado em construção. $\mathrm{O}$ autor não discute o projeto estatizante contido na proposta militar - e que, ao que tudo indica, vinha ganhando adeptos desde a década de quarenta. Em Geopolítica do Brasil (de 1958 e em recente reedição), o General Golbery do Couto e Silva já sugeria que a revolução seria a "revolução do Estado contra a sociedade; para ampliar cada vez mais a esfera e o rigor de seu controle (do Estado), sobre uma sociedade já cansada e desiludida do liberalismo fisiocrático de eras passadas". 3

A impressão que retiro da perspectiva teórica do autor talvez indique a origem dessa ausência. Dreifuss mantém inalterada a clássica visão marxista do Estado - prisioneiro de uma classe, comitê executivo da burguesia? - pouco apropriada para a realidade contemporânea, mas que, em última instância, justifica sua tese sobre o "golpe de classe". Pela ocupação dos órgãos de formulação da política econômica por membros do IPES, registra Dreifuss, dava-se a privatização das insituições do Estado; logo, abriam-se as áreas institucionais do Estado à exclusiva representação de certos interesses privados organizados. "O Estado prendia-se aos desígnios dos ativistas do IPES, que cuidavam dos problemas de coesão das diretrizes (...) O Estado de 1964 era, de fato, um Estado classista, e, acima de tudo, governado por um bloco de poder liderado pelo IPES" (p.488).

Seria interessante questionar o peso do estatismo e a crescente estatização do novo regime. O IPES proclamava a urgência de se apresentarem reformas de base "antidemagógicas" e "antiestatizantes" para enfrentar o grupo "esquerdista-trabalhista" do governo Goulart. Os empresários que hoje reclamam, e que participaram ativamente da derrocada do regime em 64, teriam sido ingênuos diante do projeto estatizante que logicamente se armava? (Ao que dizem, seus projetos "liberais-conservadores" só teriam sido bem desenvolvidos no governo Castello Branco.) A atuação dos ideólogos do IPES na defesa de interesses multinacionais é tema de dois capítulos de Dreifuss. Se um dos obje-

3 Ver, de Oliveiros Ferreira, o comentário no Suplemento Cultural de O Estado de S. Paulo, 19/07/1981. 
tivos do IPES era promover a entrada do capital estrangeiro e das multinacionais, em nome, inclusive, de uma oposição ferrenha ao capitalismo de Estado (identificado com os projetos "populistas"), o tiro saiu pela culatra. Aos investidores estrangeiros interessa, acima de tudo, a estabilidade política aliada à eficiência governamental. Porque precisariam do IPES, que se movia contra o capitalismo do Estado? Para as multinacionais interessa, num país em desenvolvimento, que o Estado assuma um papel empresarial forte, o único promotor das grandes obras de infra-estrutura. É nesse sentido que se pode entender a frustração de alguns empresários com "o desvio da rota da Revolução". Um recente artigo do economista Pedro Malan discute o "fascinante paradoxo" de ter sido exatamente a partir das gestões de Roberto Campos e Octávio Gouvêa de Bulhões (dois ilustres colaboradoresdo IPES) que se lançaram as bases para a extraordinária expansão do setor público, "apesar de toda a retórica liberal e privatista que marcou o período". ${ }^{4}$

A discussão abrange, necessariamente, aspectos por demais amplos e complexos para simples comentários. Trata-se, afinal, da discussão sobre a própria evolução do capitalismo brasileiro. Não parece heresia lembrar que a "razão do Estado" pode surgir como uma questão tipicamente capitalista. Pela necessidade ideológica de se contestar o comunismo ("o totalitário", "estatizante", etc.), o capitalismo apresentase com uma auto-imagem fictícia de portador de um projeto sempre autenticamente liberal e antiestatizante.

O que não é comprovado pela história da economia brasileira, desde a colonização (as primitivas sociedades por ações não começaram no Estado?), feita sob a égide dos empresários estatais. Lembre-se, igualmente, que a primeira experiência bem sucedida ao capitalismo de Estado ocorreu em Portugal (séc. XVI), o que. tem peso considerável na tradição brasileira, como bem o demonstrou Raymundo Faoro em Os Donos do Poder.

A estatização pós-64 não será, portanto, errática ou inovadora. Os empresários sempre dependeram do Estado, mas o Estado sempre teve, também, intenções empresariais (e aí, a "guerra das tetas" tem sua dose de verdade...). Desde o início, 64 foi o assalto dos empresários ao poder, embora, lembra Dreifuss, "protegidos e apoiados pelas Forças Armadas". Ao que parece, reclamam, hoje, quando a intervenção do

4 Pedro Samapio Malan: “O debate sobre 'estatização' no Brasil”. Dados, vol. 24, n 1, 1981. 
Estado não se faz em beneficio de seus interesses. ${ }^{5}$ Nesse sentido, uma tese interessante defendida por Dreifuss se refere à mudança ocorrida com o próprio empresariado. Não se trata, aqui, de uma interpretação global para 64, mas de mostrar como se firmou uma "nova ordem empresarial" com características próprias e distintas do empresário tradicional, aquele que cultivava uma olímpica distância em relação à política e, supostamente, ao poder.

Se é verdade, como aponta Dreifuss, que o bloco empresarial recorreu à intervenção militar apenas para desferir o "golpe final" no Estado populista, não há como abandonar, sem maiores qualificações, a tese - a meu ver ainda válida - de que os empresários acreditavam que os militares agiriam como "restauradores da ordem" e depois desalojariam o poder em seu benefício, nu papel de eficientes "leões de chácara" das grandes finanças. O que, obviamente, não ocorreu. Deve ser nesse sentido que Dreifuss sugere - mas não desenvolve, como seria desejável - que no processo de transposição do poder privado dos interesses multinacionais para o governo público, o bloco econômico dominante teria de vir a ser o Estado autoritário em que efetivamente se transformaria (p.162).

Das 814 páginas deste livro, mais da metade contém transcrições ou fac-similes de documentos. Vale a pena ler. Entre os mais importantes destacam-se aqueles que revelam a vinculação entre o IPES e o IBAD, intermediadas pelo seu braço partidário, a ADP (Ação Democrática Parlamentar, opositora da Frente Parlamentar Nacional, ambas atuantes desde o final do governo Kubitschek). A carta do banqueiro, pagador do IPES, Jorge Oscar de Mello Flores, ao vice-presidente da entidade, Glycon de Paiva, é exemplar. Trata-se de uma minuta com a proposta das "reformas de base" a serem apresentadas pelo IPES (em conjunto com o IBAD, sobretudo quanto à reforma agrária e urbana). Flores aponta as vantagens dessa proposta, com ênfase nos "aspectos técnicos" (contra as propostas "demagógicas" dos "agitadores") e visando colocar a esquerda na defensiva, ao mesmo tempo em que projetava uma imagem favorável, e "progressista", do IPES. A última "vantagem", segundo a carta, seria conseguir, eventualmente, medidas benéficas. ao país e ao regime democrático vigente" (p. 721).

5 A indignação do jornalista Otávio Tirso de Andrade (um defensor convicto da direita mais tradicional) é elucidativa: "O Estado a que chegamos - como definiria o atual regime o saudoso Barão de Itararé - não é o ambicionado pelos liberais mobilizados contra o advento da República Sindicalista. Não foi para elevar os uéki da vida aos arquiducados do estatismo que a pequena burguesia urbana desfilou 'nas marchas com Deus', conta a anarquia janguista”. Jornal do Brasil, 13/07/1981, p. 11. 
No Apêndice destaca-se, também, por outros motivos, os documentos sobre as relações entre Sonia Seganfredo (agitadora de direita, famosa "dedo-duro" da Faculdade Nacional de Filosofia, no Rio de Janeiro) e o IPES, a respeito da publicação de seu livreto intitulado UNE, Instrumento de Subversão. Em obra tão séria esta correspondência consegue ser hilariante. A carta do então tenente Heitor de Aquino Ferreira em papel nominal timbrado! - para Seganfredo, propondo cumplicidade e segredos conspiratórios (em relação à entrevista da autora com o General Golbery) mais parece arquivo do Mickey Mouse contra os Irmãos Metralha. E as patéticas cartas da escritora, querendo ser "reconhecida" como militante do IPES (já "estava muito marcada") mostram, com humor negro, o triste fim dos delatores.

Esta extensa parte documental, justamente por conferir à tese de Dreifuss um alto valor de seriedade e competência, exigiria uma errata para as próximas (e, certamente, numerosas) edições. No arrolamento de milhares de nomes, é compreensível que se cometam enganos. A grafia incorreta de nomes próprios pode, no entanto, causar equívocos intrigantes, como, por exemplo, confundir o financista carioca do IPES, Afonso Almiro, com o nome do político petebista, ex-Ministro de Trabalho de Goulart, Almino Affonso. O que me parece mais importante nas incorreções das listagens e, repito, importante exatamente pela seriedade da pesquisa - se refere à agregação de pessoas as mais diversas, com intenções, objetivos e formações extremamente díspares. A maior parte dos ipesianos, militantes ou contribuintes, eram diretores de empresas. $\mathrm{O}$ que não significa que todos os membros da diretoria de uma determinada empresa participassem do IPES. Nesse sentido, por exemplo, o que haveria em comum entre o milionário Cândido Guinle de Paula Machado e o intelectual Alceu de Amoroso Lima, apresentados lado a lado, como diretores da Editora Agir?

A ampla massa de informações, no corpo do livro, surge intercalada com a encampação explícita (e, a meu ver, algumas vezes pouco apropriada) de conceitos gramscianos como "sociedade civil", "hegemonia", "intelectual orgânico", etc. A perspectiva teórica abrange, ainda, desde o debate sobre o papel do Estado em Milliband e Poulantzas, até os "anéis burocráticos" de Fernando Henrique Cardoso, passando pela "modernização conservadora" de Barrington Moore. O livro é, pois, de árdua leitura em alguns momentos o acompanhamento de tantos dados com a sequiência do argumento é, literalmente, atordoante - mas será sempre estimulante, quando não surpreendente. Referência obrigatória para todos os que se dedicam ao estudo das malhas do poder no Brasil, a partir do governo Kubitschek, o livro se beneficiaria, para o público mais amplo, de um paciente e generoso trabalho de simplificação metodológica, assim como de maior clareza na interligação dos capítulos e integração das notas. 


\section{RESUMOS/ABSTRACTS}

\section{4: UM GOLPE DE CLASSE? (SOBRE UM LIVRO DE RENÉ DREIFUSS)}

Republica-se aqui o comentário feito na época da sua publicação do importante livro do recentemente falecido cientista político René Armand Dreifuss sobre o papel de uma "elite orgânica" de orientação empresarial na desestabilização do regime democrático pré-1964, no sentido da criação de uma "ordem empresarial" após o "golpe de classe" de 1964 (1964: a conquista do Estado - ação política, poder e golpe de classe). Para a autora a noção de "golpe de classe" é insuficiente para dar conta da dinâmica política e econômica da época, assim como se revelaram frustrados os esforços para constituir uma "ordem empresarial", em vista do impulso estatizante promovido pelo regime militar. Destaca-se, contudo, o valor do livro, que é aqui relembrado, junto com o nome do seu autor.

Palavras-chave: Brasil: empresariado; Brasil: regime militar.

\section{4: A CLASS PUTSCH? (ABOUT A BOOK BY RENÉ DREIFUSS)}

The commentary made at the time of its publication about the important book by the recently deceased political scientist René Armand Dreifuss on the role of an "organ ic elite" in the overthrowing of the pre-1964 Brazilian regime aiming at an "entrepreneurial order" after the "class putsch" of 1964 is here republished. It is argued that the idea of "class putsch" is too narrow to cover the political and economic dynamics of the epoch, and that the efforts to constitute an "entrepreneurial order" were frustrated by the impulse toward a growth of State functions promoted by the military regime. However, the review emphasizes the merits of the book, which is here brought to memory along with the name of its author.

Keywords: Brazil: entrepreneurs; Brazil: military regime 